\title{
Impact of Cyclone Yasi on the Wreck of the SS Yongala Documented by Comparative Multibeam Bathymetry Analysis
}

\author{
Thomas C. Stieglitz ${ }^{1,2}$ and Paddy Waterson ${ }^{3}$
}

1 Marine Geophysics Laboratory, School of Engineering and Physical Sciences, James Cook University, Townsville QLD 4811, Australia thomas.stieglitz@jcu.edu.au

2 Centre for Tropical Water and Aquatic Ecosystem Research (TropWATER), James Cook University, Townsville QLD 4811, Australia

3 Heritage Branch, Department of Environment and Heritage Protection, GPO Box 2454, Brisbane QLD 4001, Australia paddy.waterson@ehp.qld.gov.au

\begin{abstract}
In February 2011, north Queensland experienced one of the largest and most severe tropical cyclones on record. Category 5 Cyclone Yasi caused substantial structural damage not only on land, but also at sea, including to the historic shipwreck of the SS Yongala. The Yongala is of high cultural and natural heritage value and is a major dive tourism attraction. As part of a Queensland Government initiative to document the degree of damage by Cyclone Yasi, changes to its structure were documented by comparative analysis of multibeam bathymetry data of the wreck collected in August 2004 and May 2011 (i.e. pre- and post-Yasi respectively). The storm had a significant physical impact on the c.110m-long wreck. The most pronounced changes occurred in the forward section of the wreck. A $35 \mathrm{~m}$ section forward of the central deck citadel has rotated around its own axis and the bow dropped more than $5 \mathrm{~m}$ in depth. Minor deformations were observed at the stern of the wreck and debris was identified on the seafloor around the wreck. The impacts of the cyclone will exacerbate deterioration. It is very likely that the wreck's hull will rupture in the short- to medium-term, especially if further extreme weather events occur. Together with visual observations, the results of this study will inform ongoing site management by contributing to the identification of key risk areas, and help to establish policies and procedures to address damage to the wreck's integrity in the future.
\end{abstract}

\section{Introduction: The Wreck of the SS Yongala}

Adelaide Steamship Company vessel Yongala was a luxury passenger steamer. Built in 1903, the SS Yongala had operated extensively in Australian waters before being assigned the route between Melbourne and Cairns in 1907 (Moran 2001:12). On 23 March 1911, the vessel left Mackay for Townsville carrying at least 122 people (Marine Board of Queensland 1911:2). The Yongala was last sighted by the light keeper at Dent Island five hours after departing Mackay (Brisbane Courier 21 June 1911:5; Moran 2001:14). Communications at the time were limited and the ship departed Mackay without knowing that it was sailing into a cyclone, which caught and sank the vessel with the loss of all on board (Moran 2001:13). Wreckage was later found washed up on beaches from Hinchinbrook Island to Bowen, but despite an extensive search there was no sign of the vessel or those on board (Moran 2001:14). The Marine Board of Queensland was satisfied with the ability of the captain and the seaworthiness of the vessel and concluded that the cause of the loss of the ship was unknown. The event did however confirm the Marine Board's concerns about the risks of navigating the Queensland coast during the cyclone months (Brisbane Courier 21 June 1911:5; Marine Board of Queensland 1911:2). The actual fate of the SS Yongala was not known until after World War II. In 1947, a shoal previously located off Cape Bowling Green was investigated by a navy hydrographic vessel, and reported to be a large wreck (Gleeson 2000:95). Definitive proof of its identity was ultimately provided in 1958 by the serial number of the recovered purser's safe (Gleeson 2000:96-102; Moran 2001:21-22).

The wreck is sitting on a sandy ocean floor with a maximum depth of $30 \mathrm{~m}$, and rises to a minimum depth of approximately $14 \mathrm{~m}$. Much of the upper superstructure has deteriorated and the hull is covered by diverse sessile organisms, forming a visually spectacular artificial coral reef. It attracts a significant diversity in marine life, making the wreck an important element of the local ecology (Malcolm et al. 1999; Stieglitz 2013). Today, the wreck is one of the most visited dive sites in the Great Barrier Reef (c.6500 divers per year over the last 10 years). To help manage impacts, a 'Protected Zone' was declared within a $800 \mathrm{~m}$ radius of the wreck. A permit is now required under the Historic Shipwrecks Act 1976 to enter the protected zone (Viduka 2006:62-63).

The wreck has been impacted by previous cyclonic events, most notably Cyclone Aivu in 1989, which removed a memorial plinth and considerable sections of the covering benthos (Moran 2001:42). Cyclone Larry in 2006 caused some minor loss of coral cover, but while new holes appeared in the deck plating, there was no major damage to the wreck's structural elements (Viduka 2007:135).

\section{Cyclone Yasi}

On 3 February 2011, Cyclone Yasi crossed the north Queensland coast around Cardwell, causing widespread damage. The system was extraordinarily large. At the location of the Yongala c. $200 \mathrm{~km}$ south-southeast of the storm's main path, wind force remained destructive, equivalent to a Category 2 cyclone at this location (Australian Bureau of Meteorology 2011) (Figure 1). Indeed, wave data in the vicinity of the wreck indicate maximum trough to crest wave heights in excess of $10 \mathrm{~m}$ (Great Barrier Reef Ocean Observing System (GBROOS) - Yongala National Reference Station, unpublished data). CSIRO oceanographer George Cresswell (pers. comm., 


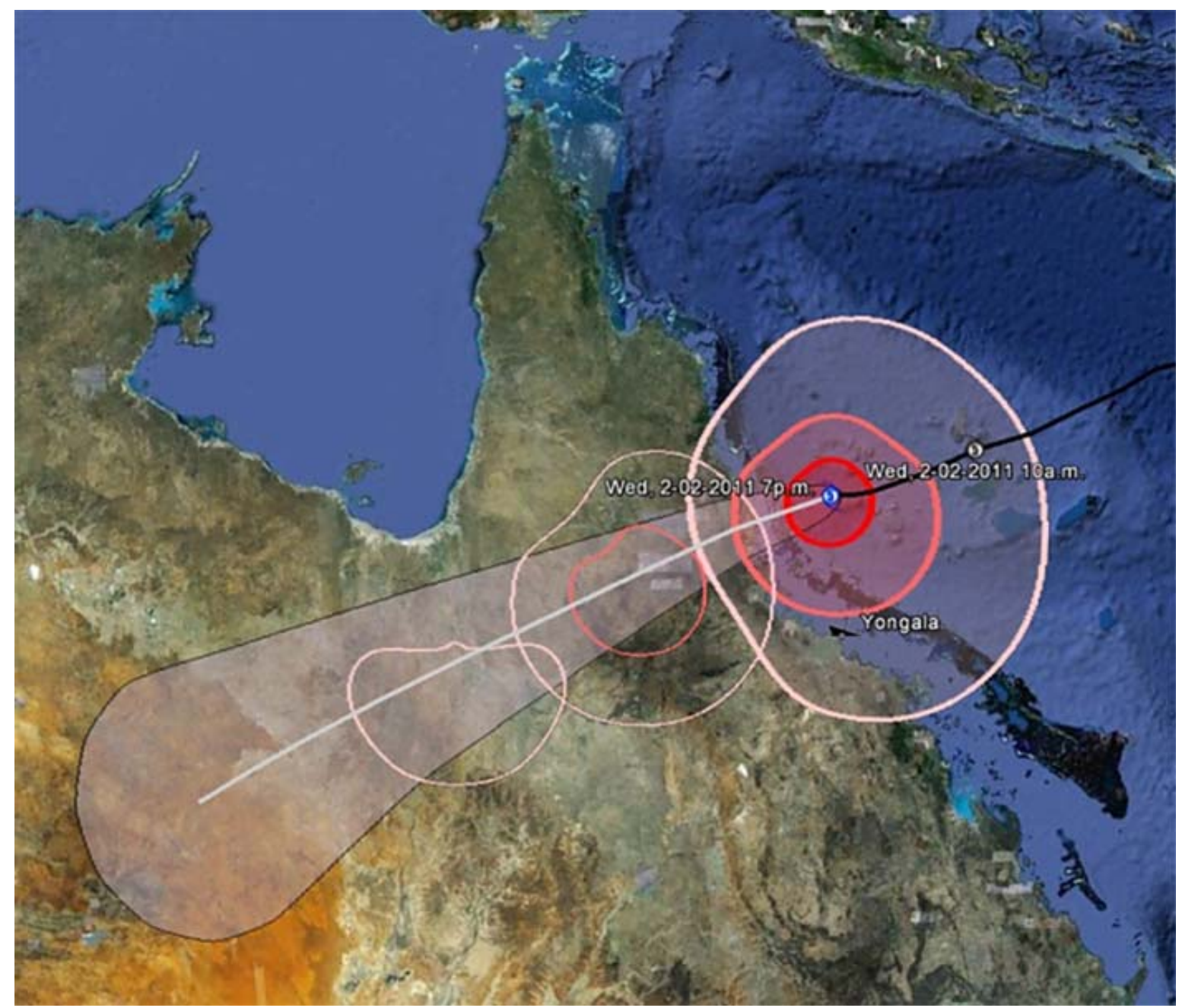

Figure 1. Track of Cyclone Yasi in early February 2011. The wreck of the Yongala is located on the southern edge of the destructive wind zone (light red) (AIMS/Google Earth).

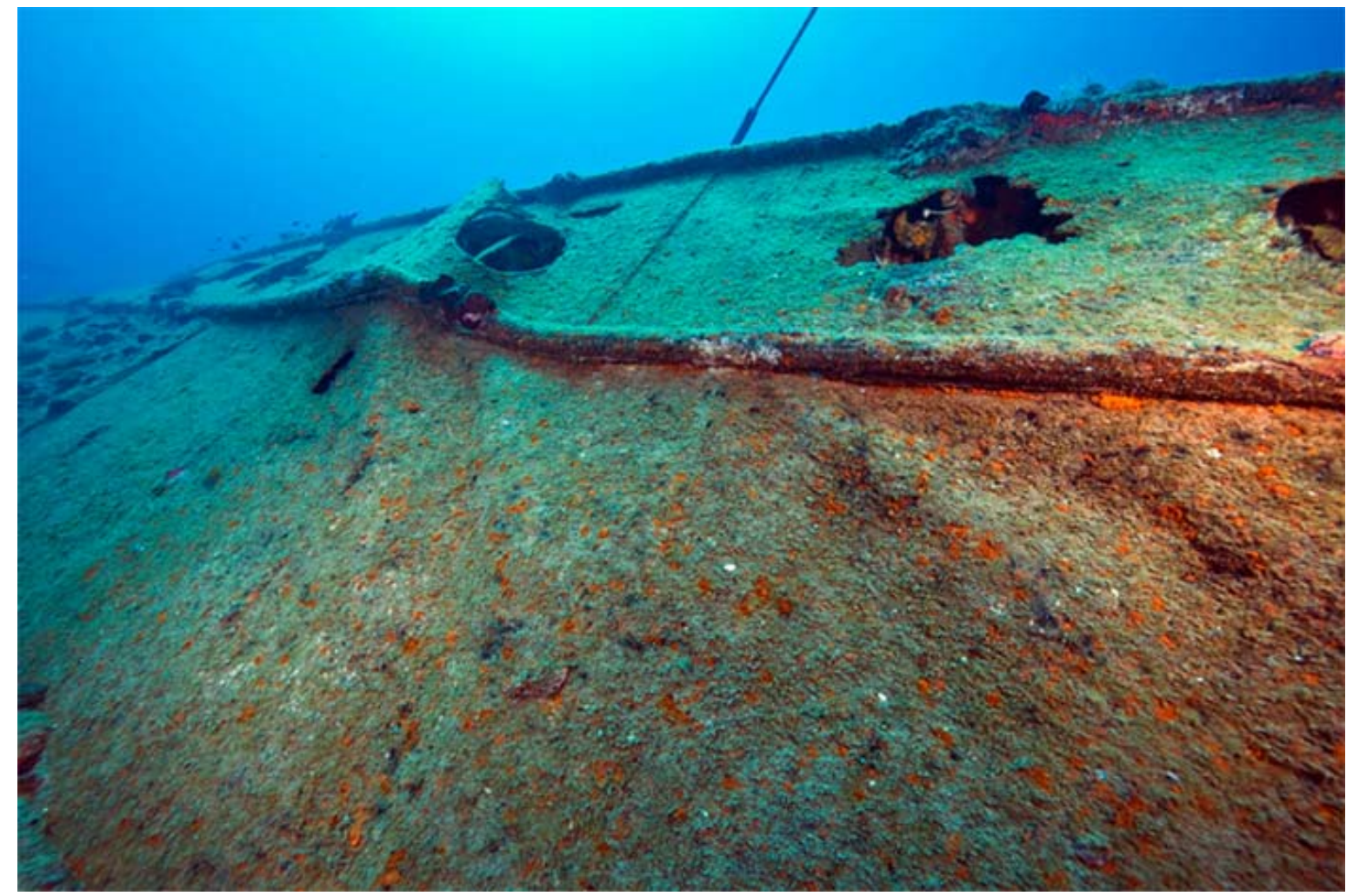

Figure 2. Hull buckling and warping is clearly visible in dive inspections after Cyclone Yasi's passage (Photograph: David Wachenfeld, Triggerfish Images). 
17 July 2012) has further estimated the 'to-and-fro' water movement across the surface of the wreck to be $5 \mathrm{~m}$ per second or 10 knots. Initial reports from divers indicated that the wreck of the SS Yongala had received significant permanent damage to its structure (Figure 2). A preliminary site inspection by a government dive team confirmed the high degree of impact by visual observations, but the size of the wreck (c.110m in length), the low visibility and relative depth complicated the collection of quantifiable data on the scale of impact (Waterson 2012).

\section{This Study}

As part of a Queensland Government initiative to document the degree of damage caused by Cyclone Yasi, changes to the Yongala's structure were documented by comparative analysis of multibeam bathymetry data. High-resolution multibeam bathymetry data of the wreck were collected in May 2011 for comparison with similar pre-Yasi data collected in August 2004 by the authors. This mapping technique, while expensive, has become an accepted method for monitoring changes in underwater sites due to their accuracy and high level of detail (Bowens 2009:106). Together with visual observations, the results of this study will inform ongoing site management, by contributing to the identification of key risk areas, and help to establish policies and procedures to address breaches in the wreck's integrity in the future.

\section{Methods \\ Data Collection-Post Yasi}

High-resolution multibeam bathymetry data were recorded on the wreck site with a pole-mounted multibeam echosounder RESON Seabat 8101 on 13 May 2011. The Seabat 8101 multibeam echosounder has 101 beams with an athwartship angle of $1.5^{\circ}$ for each beam at a depth resolution of $1.25 \mathrm{~cm}$. Ping rate was equal to or greater than $20 \mathrm{~Hz}$ at all times for this survey. Vessel track, heading and motion were recorded with a differential GPS, the vessel's gyrocompass and a TSS DMS dynamic motion sensor mounted at the centre of gravity of the vessel respectively. Multibeam data were time-stamped with a one-pulse-per-second signal from the GPS, eliminating time delays (latency) between sensors. All data streams were concurrently recorded using QINSy 8 survey software.

The multibeam survey consisted of tracks approximately parallel to the orientation of the main (NS) axis of the wreck. Vessel speed varied between 2 and 5 knots. The survey was designed to be of very high quality at a horizontal and vertical resolution of $0.5 \mathrm{~m}$ and $0.1 \mathrm{~m}$ respectively. The distance between tracks was $10 \mathrm{~m}$ or less, such that significantly greater than $100 \%$ overlap was achieved (i.e. each point on the seafloor was ensonified multiple times), which resulted in optimum spatial resolution. Data collected with the outer 20 beams on each side were deemed of insufficient quality for this purpose and were excluded.

\section{Data Collection Pre-Yasi}

On 20 August 2004, a similar survey was carried out with a specialised high-resolution echosounder, the RESON Seabat 8125. This echosounder is similar in characteristics to the Seabat 8101, however at an athwartship angle of $0.5^{\circ}$ it has a greater spatial resolution, resulting in slightly different sounding density between datasets. In the 2004 survey, lines were recorded perpendicular to the wreck. Ad hoc repeat surveys in 2004 and 2007 with the Seabat 8101 at less than 100\% coverage show no significant changes in the external structure of the wreck in comparison with the Seabat 8125 data. This indicates that other cyclones between 2004 and 2011 (e.g. Cyclone Larry) had no effect on the wreck as measurable by this method. Data collected in August 2004 are thus representative for pre-Yasi conditions.

\section{Data Processing}

Multibeam data were processed with the software SWATHED of the Ocean Mapping Group of the University of New Brunswick, Canada. Sonar ranges measured with the echosounder were converted to depth by integrating the range, GPS, heading and motion data whereby the acoustic data were corrected for refraction using a representative sound velocity profile collected onsite. Water level variations were corrected using data from the nearby tidal prediction station at Stanley Reef. Static offsets between the GPS antenna, motion sensor and echosounder head on the vessel were measured with a tape measure to the nearest $5 \mathrm{~cm}$ and dynamic offsets (roll, pitch and yaw) were calculated by standard procedures (patch test) using the wreck data. False soundings were eliminated by range filtering and manual inspection. Subsequently, 3D point data were imported into the 3D geospatial processing and analysis software IVS3D Fledermaus V7.3 for further processing and visualisation.

A '3D cloud' object was created, consisting of all XYZ (easting, northing, depth) points of the wreck and the seafloor immediately surrounding the wreck. Data were inspected for consistency between the two models (2004 and 2011 data). Tidal water level correction for the 2004 model was adjusted so that the average depth of the seafloor was consistent with the average depth in 2011. In addition, the average absolute position of the wreck in 2011 was found to be systematically offset by $2 \mathrm{~m}$ to the west in comparison with the 2004 data. This offset is within GPS positioning error, and thus was deemed an artefact of sampling and was corrected.

From the corrected 3D cloud data, an XYZ shallowbiased grid at $0.5 \mathrm{~m}$ resolution was calculated, whereby for each grid cell, the shallowest point was chosen, in order to best represent the shape of hull and superstructure for data comparison purposes. The difference between 3D cloud and grid is that in a grid, for each easting and northing only one depth value exists, whereas for 3D cloud data, multiple points can share the same $\mathrm{X}$ and $\mathrm{Y}$ coordinates.

Concurrently collected backscatter (sidescan) data yielded no additional information, and is not reported here. Data are visualised in WGS 84, Universal Transverse Mercator (UTM) Projection, Zone 55S. Depth is reported with reference to the lowest astronomical tide (LAT) of Stanley Reef, the nearest tidal prediction station of the Australian Hydrographic Office. Horizontal resolution of the generated datasets is $0.5 \mathrm{~m}$, and thus changes in this order or larger are detected. In 3D images, no vertical exaggeration was applied.

Changes to the external structure of the wreck between 2004 and 2011 were determined by quantitative comparison of 2004 and 2011 grid data by calculation of 

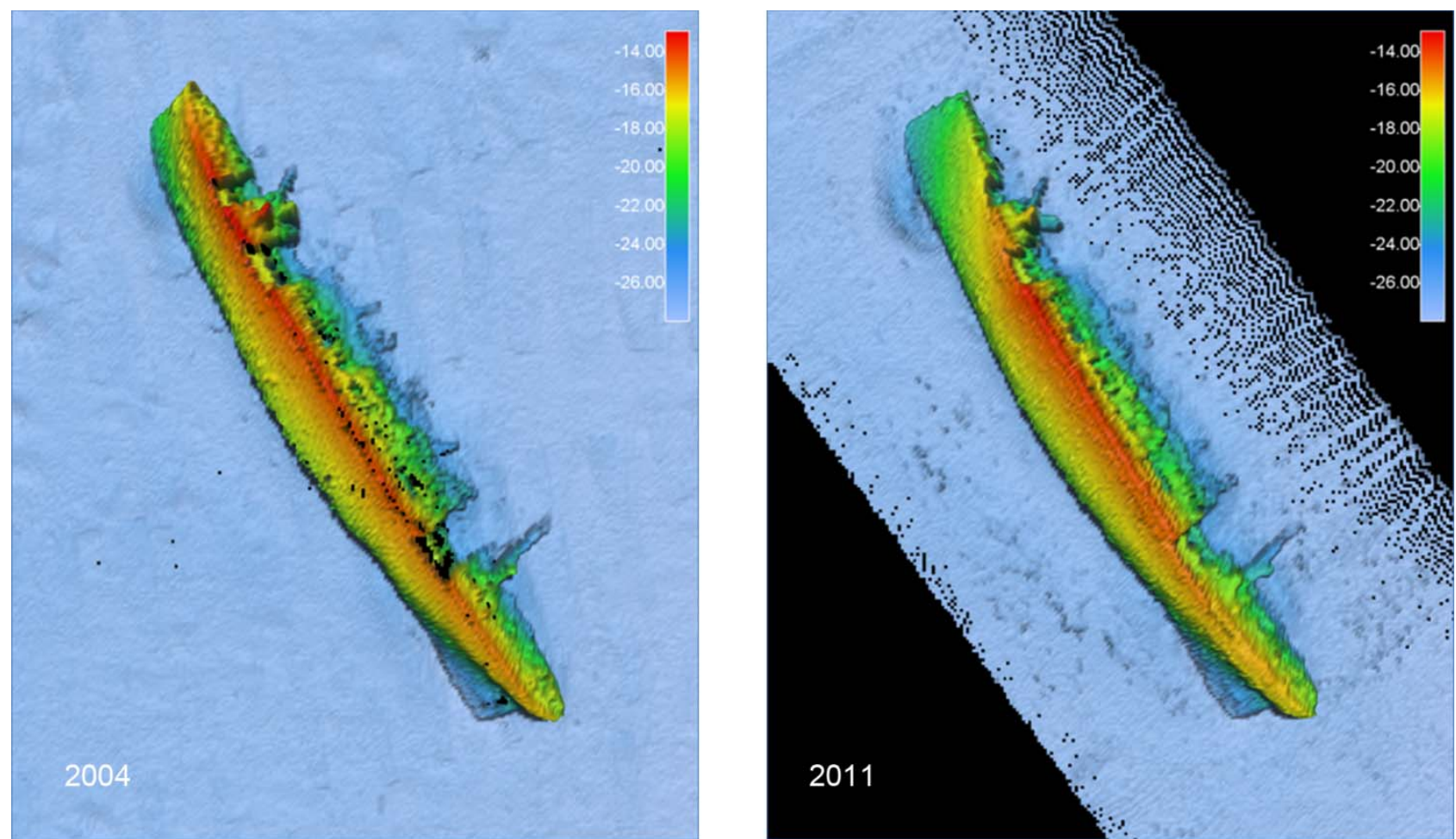

Figure 3. Plan view of color-coded sun-shaded bathymetry grid (shoal biased). The digital terrain models are displayed with an identical colour-code for comparison (legend shows depth in metres LAT).

the difference of the two grid surfaces and extraction of cross-sections of the wreck across the hull. Additional qualitative visual inspection of $3 \mathrm{D}$ point cloud data was used to identify small-scale changes not well-represented by the grid data.

\section{Results}

Major features such as hull shape, cargo holds and superstructure are prominently visible in both datasets (Figure 3). The $110 \mathrm{~m}$-long wreck is oriented in an approximate NNW-SSE direction. Water depth of the surrounding seafloor is approximately $27 \mathrm{~m}$ lowest astronomical tide (LAT), and the wreck rises to less than $14 \mathrm{~m}$ depth. Overall, the position of the wreck remained unchanged. Importantly, it did not rotate or shift in $\mathrm{X}-\mathrm{Y}$ direction.

The most pronounced changes occurred in a c.35mlong section forward of the first cargo hold (highlighted in red, Figure 4). The bow at its tip has dropped in height by just over $5 \mathrm{~m}$. The forward section of the hull has rotated towards the east, with a pivot point located 35-40m aft of the bow (Figures 5-6). Hull cross-sections X11 to X14 in Figure 6 provide a quantitative determination of this rotation around the wreck's axis.

The results of the survey and the impacts of the cyclone are clearly illustrated in 3D images (Figures 7-8). The main body of the wreck amidships is in the same position as pre-Yasi and appears to be largely stable (Figures 4, 6). Impacts in the centre of the ship have been largely restricted to the exposed deck levels and superstructure (Figure 7). For example, the forward derrick mast is now at a less pronounced angle to the ship's deck (Figure 7), consistent with the identified twisting and rotation of the forward section of the ship. The stern of the wreck has only slightly dropped (Figures 4, 7). Cross-sections X03 to X05 (Appendix A), representing the aft 30m section of the wreck, show small, possibly rotational variations between 2004 and 2011 data.

The survey also produced clear evidence of debris fields surrounding the wreck (Figure 8). A substantial number of new meter-scale positive bathymetric features were identified, especially to the west and southeast of the main wreck. New features are also evident along the base of the deck level (Figure 7), likely a combination of exposed wreckage and superstructure damaged during the storm.

\section{Discussion}

The comparative analysis of pre- and post-Cyclone Yasi bathymetry data clearly illustrate Yasi’s profound effects on the physical fabric of the wreck, particularly in the bow and to a lesser extent the stern. A similar quantitative assessment of structural damage at this scale is not easily obtainable with other methods, for example, by visual inspections. In addition, while limited in spatial resolution, this 3D-mapping method allows for a more quantitative assessment than the more traditional, and cheaper, 2D side-scan sonar technology. The information obtained from the multibeam analysis has also assisted with directing dive teams to areas of interest.

Post-Yasi dive inspections (not reported in detail here) are consistent with the assessment of multibeam data. Visual inspections by divers provided important supplementary information on conservation issues (e.g. areas of active corrosion) and identified specific structural elements, which although at a smaller spatial scale, facilitated a more nuanced understanding of structural decay and physical changes. Divers immediately observed signs of stress and fatigue at the outer hull (e.g. Figure 2). 


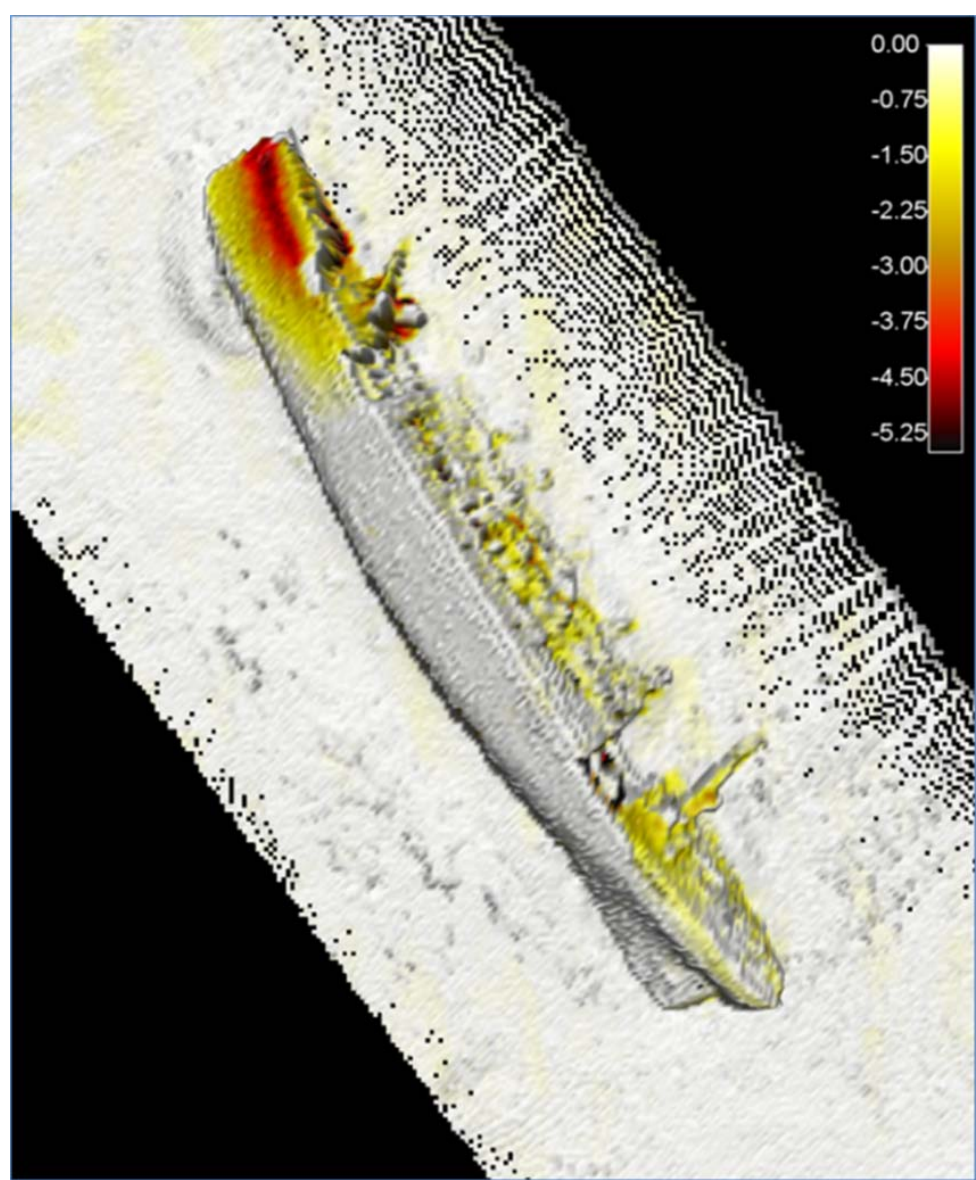

Figure 4. Plan view of difference in depth between 2004 and 2011 shoal-biased grid data (i.e. difference between the datasets shown in Figure 3), draped over the 2011 bathymetry data. The colour code denotes changes in meter for each grid cell. Red colours indicates largest changes between data sets at the bow section.

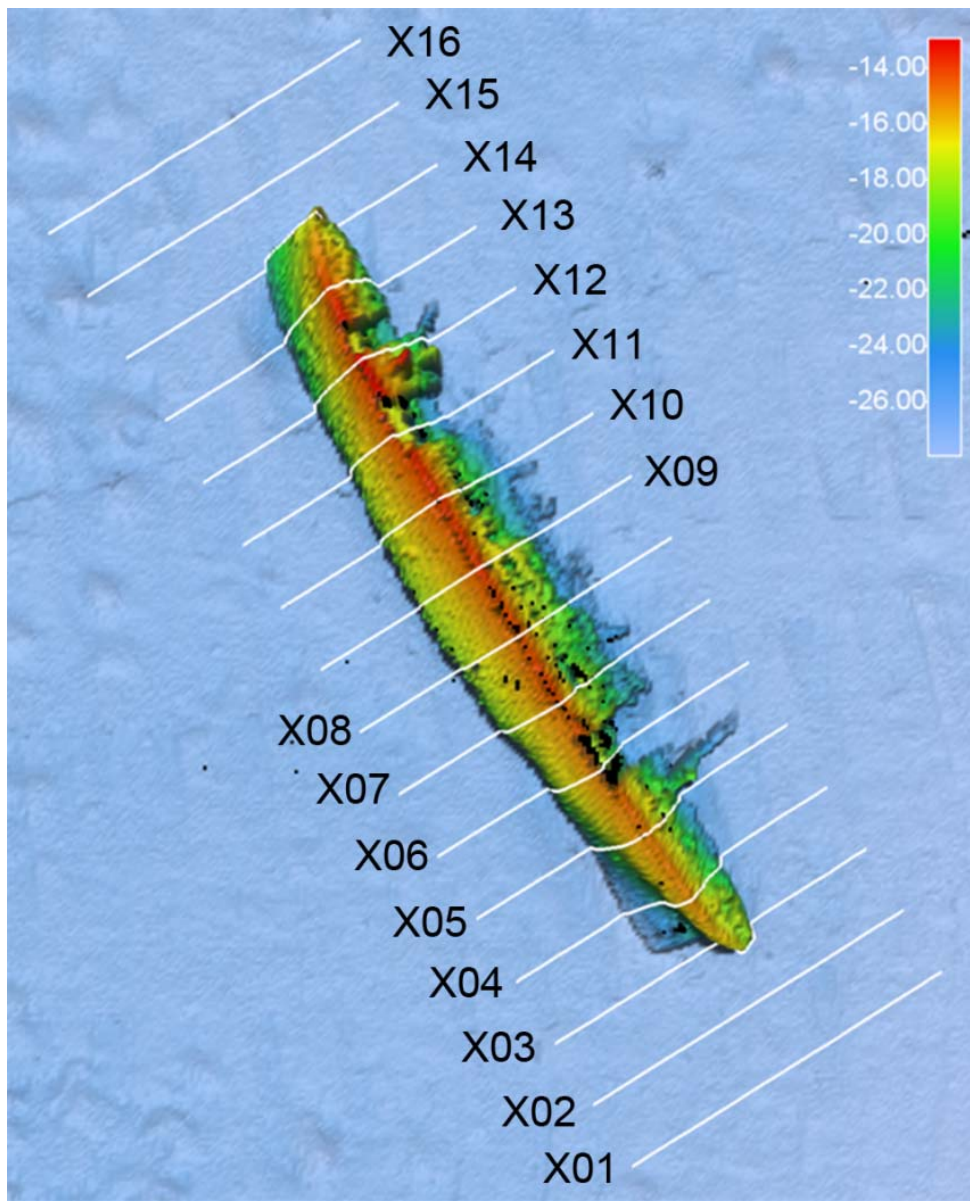

Figure 5. Locations of sections across hull in 10m intervals shown in Figure 6 and Appendix A. 

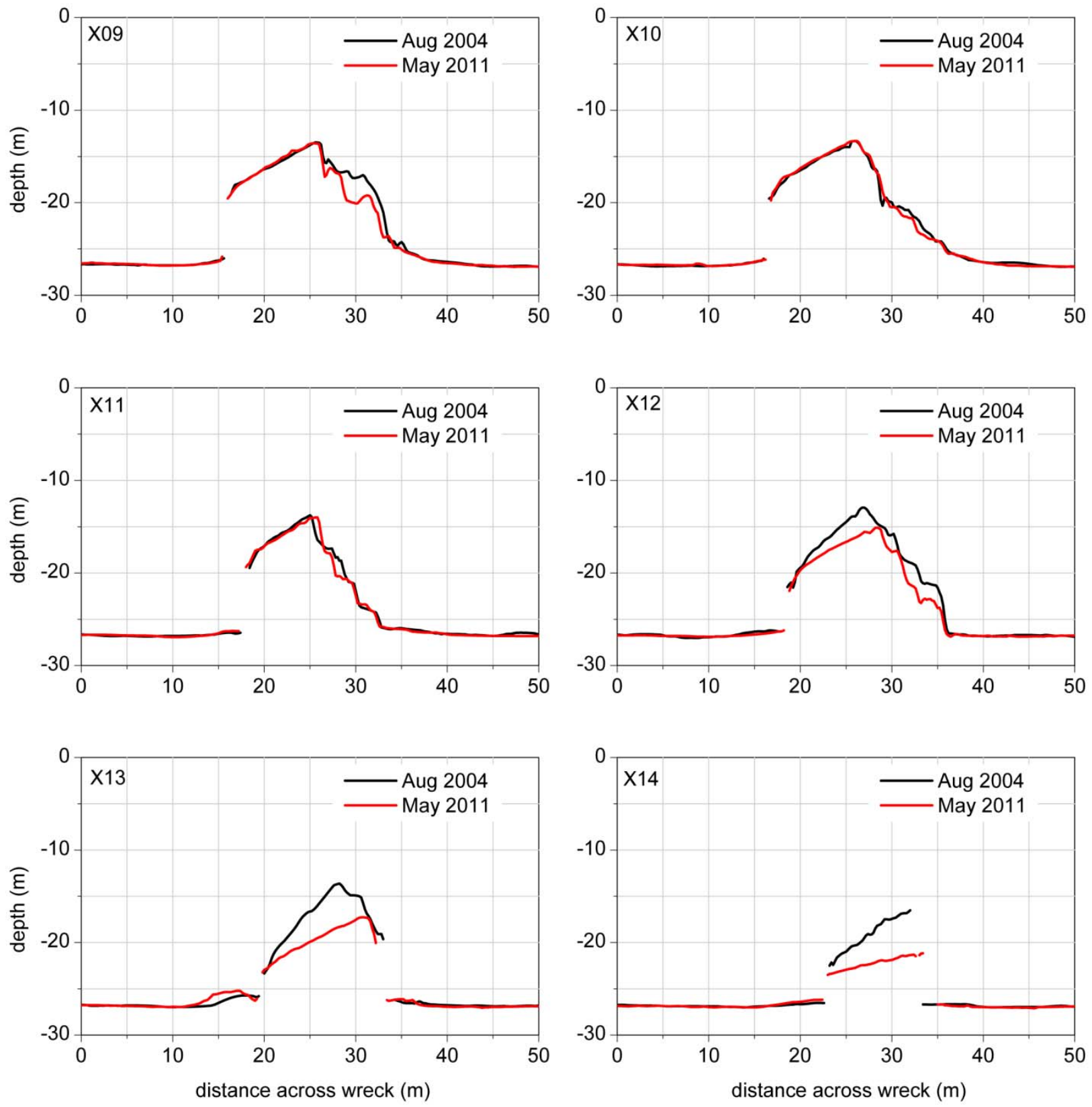

Figure 6. Quantitative comparison of wreck morphology in sections across the hull forward from the centre of the wreck (X09-X14). Cross-sections are drawn from SW to NE. The rotation and drop of the bow section is evident in sections X11-X14. For completeness, all sections X01-X16 are shown in Appendix A. 

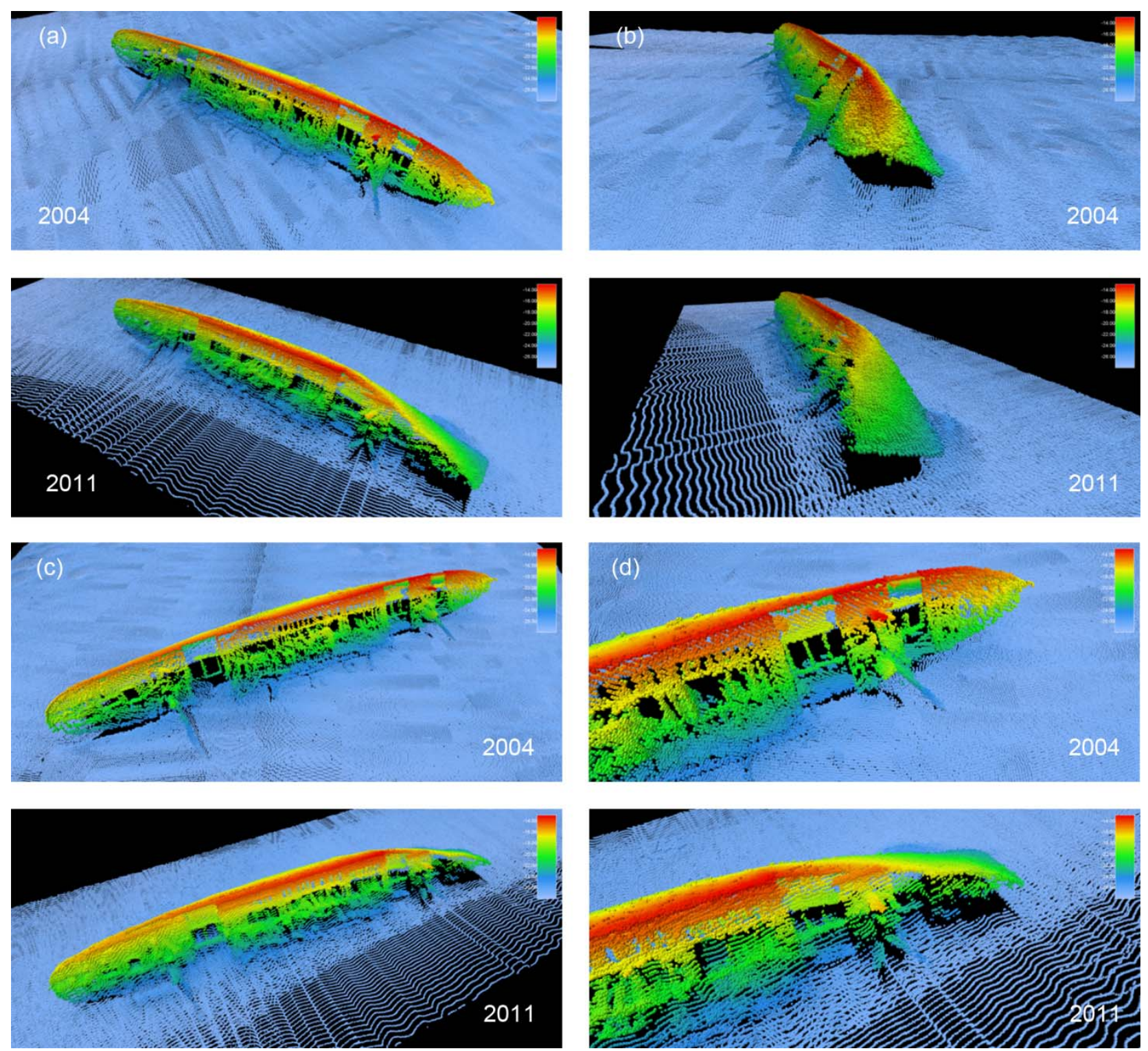

Figure 7. Qualitative comparison of 3D point cloud data. 3D view from (a) ENE, (b) N and (c \& d) E respectively. The rotation and drop of the bow section and rearrangement of forward masts/stacks are prominently visible. In addition, a small difference is noticeable at the stern section: the deck part has slightly dropped (compare colour in (c)). At the stern, the difference in sounding density of the superstructure may preclude or mask the detection of some small-scale changes.
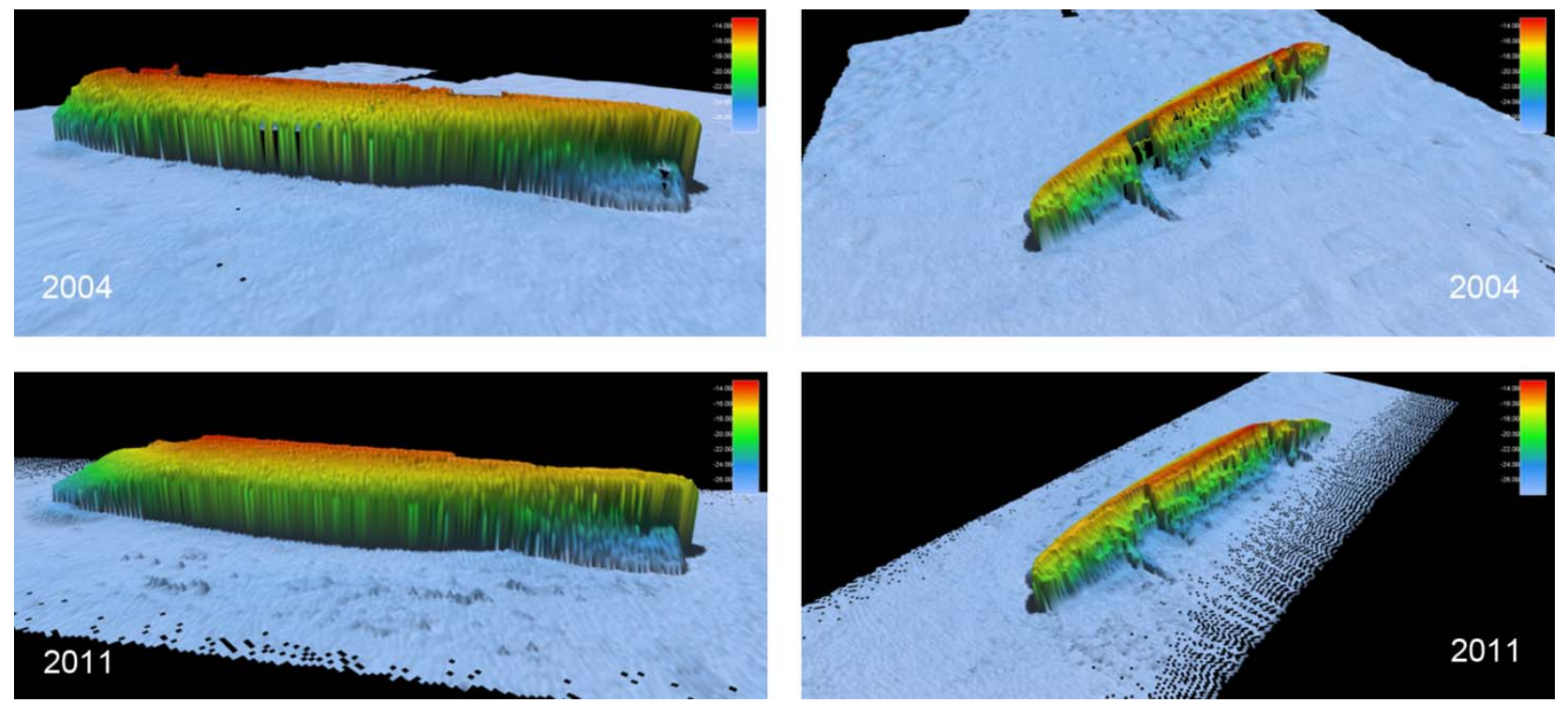

Figure 8. 3D view of the shoal-biased grid from approximately SE (left) and SSE (right), indicating debris on the seafloor to the west of to the west of the hull and to the east of the stern section of the wreck. 
Numerous openings have appeared where benthos has been removed exposing either pre-existing corrosion holes or paper thin metal to the highly corrosive environment. Where metal integrity is relatively high, stress forces have created buckles or ripples in the hull (G. Hewitt, pers. comm., 10 September 2012). In sections, cracks are running across the deck from port to starboard, while in others the hull plating is separating. The openings to the two forward holds have buckled, and sections of the central deck citadel have collapsed, causing some materials to fall onto the adjacent seafloor. In both multibeam and visual observations, the forward section of the wreck's upper port side showed the most obvious signs of physical stress, with buckling and warping of the exposed metal hull (Figure 2). It is interesting to note that visual inspection revealed significantly more coral concretions remaining on the aft section compared to the upper centre and forward sections, which have been left virtually bare by Yasi, possibly indicating smaller impact by shear forces towards aft. However it is possible that the poor ductility of hard-bodied epifauna and concretions also contributed, and that their loss was proportional to the level of movement in the hull's shell plating (G. Hewitt, pers. comm., 10 September 2012).

Post-Yasi, the wreck must be considered to be under increased mechanical stress. The increased damage, the rotation in the ship's hull at the terminal ends and the loss of the ship's protective crust will collectively have a substantial negative impact on the wreck's integrity. While the regrowth of protective corals will have an overall net benefit and help the wreck in establishing a relative equilibrium with its environment, there is some debate that the associated increased weight may cause additional stress (MacLeod and Steyne 2011:355; G. Hewitt, pers. comm., 10 September 2012). Regardless, there is broad consensus that deterioration will be exacerbated by future severe weather and scouring events (Quinn 2006), both of which are likely to occur at the Yongala site. Should scouring remove the supporting sediments from underneath the stressed bow section, additional deformation is likely. Further comparative monitoring using multibeam technology will not only enable changes to the wreck to be tracked but will also help identify and quantify alterations in seafloor sediment.

Many of the major changes identified after Cyclone Yasi are broadly consistent with the Riley Waterline Theory on the decay of iron-hulled ships (MacLeod and Viduka 2011; McCarthy 2000). This theory argues that iron-hulled vessels commonly disintegrate in a consistent pattern, with the strongly-built bow and stern triangles separating from the weaker central cargo and amidships sections. The central sections will then deteriorate relatively quickly, although the rate will depend upon the nature of the seabed and substrate. Eventually, 'an exposed iron hulled wreck will commonly appear with the bow and stern triangles separated on their side, with a flattened central hull and a machinery section dominated by the engine and boilers' (McCarthy 2000:101). The significant movement of the Yongala's bow triangle and the smaller changes to the stern observed by the multibeam analyses appears consistent with Riley's model and warrants further investigation. As indicated by Hewitt (pers. comm., 10 September 2012), the direct application of the Waterline Theory is yet to be fully established given that Riley clearly stated his model was based on vessels on an even keel (McCarthy 2000:97) and the main body of the Yongala lies on angle of approximately $65^{\circ}$. The eventual separation of the bow and/or stern would be particularly problematic for the Yongala as the ship is archaeologically intact and lying on its side. While some breaches and the exposure of artefacts have already occurred, the separation of the bow and/or stern would likely cause internal artefactual material to be exposed and to scatter, removing it from its current context and altering its micro-environment.

At present, most of the known debris field and newly identified anomalies have not been properly assessed. Their proximity to the wreck clearly suggests that they are associated with the Yongala, but they remain to be confirmed as archaeological or biological debris (i.e. abraded coral and shellfish cover).

It is interesting to note that a preliminary analysis of similar multibeam data collected from the wreck of the Lady Bowen did not indicate changes as large as observed at the Yongala. The Lady Bowen lies further north, in the direct path of Cyclone Yasi but in slightly deeper water, and the site is somewhat protected by nearby reefs. A number of reasons likely contribute to this difference in effect, most prominently the smaller wind fetch at the site in comparison with the Yongala's resting place. It is reasonable to assume that the greatest effect of a cyclone on structures on the seabed is not necessarily associated with the greatest above-water wind speeds, but with greatest oceanographic response in the form of cyclonedriven currents and waves.

\section{Conclusions}

In summary, large-scale damage to the wreck of the Yongala was documented and quantified by comparative analysis of pre- and post-Cyclone Yasi multibeam bathymetry data. Changes on the scale of meters to tens of meters are difficult to document and quantify with more traditional observational methods by diving, and it is suggested that for large significant shipwrecks with a suitable profile, similar multibeam bathymetry data should be collected to provide a baseline for future studies of structural changes to iron-hulled shipwrecks and to develop a better understanding on how severe weather events impact on such sites.

Together with visual observations, the results of this study will inform ongoing site management of the Yongala, by contributing to the identification of key risk areas, in order to establish policies and procedures to handle any significant damage to the wreck's integrity in the future.

\section{Acknowledgements}

Data were collected in 2004 and 2011 on the RV James Kirby. The professional support by the vessel crew, Don Battersby and Gerard Topping, is gratefully acknowledged. Additional technical support in 2011 was provided by Michael Santarossa, Ross Marchant and Fernando Andutta (James Cook University). Robert Slater from the Port of Brisbane generously provided a spare license dongle for the survey software. Douglas Bergersen from Acoustic Imaging Pty Ltd is thanked for arranging this loan. Data collection in 2004 was funded by the Cooperative Research Centre for Coastal Zone, Estuary and Waterway Management (Coastal CRC). The Heritage Branch of the 
Queensland Government partially funded the 2011 study under the Australian National Historic Shipwrecks Program and issued permit 10017 to carry out this work. The Queensland Parks and Wildlife Service coordinated the initial government dive inspection. Dr Ian McLeod (Western Australian Museum) and Geoffrey Hewitt (La Trobe University) provided valuable comments on the initial Heritage Branch report. Dr George Cresswell (CSIRO) and Tony Auden (BOM) generously undertook a preliminary hydrographic analysis of Cyclone Yasi data. Thanks to Paul Crocombe (Adrenalin Dive) and Heather Batrick (Yongala Dive) for initial reporting of damage and their support of ongoing research at the Yongala, and to David Nutley and one anonymous reviewer for their constructive comments on the manuscript.

\section{References}

Australian Bureau of Meteorology 2011 Severe Tropical Cyclone Yasi. Retrieved 11 November 2011 from http://www.bom.gov.au/cyclone/history/yasi.shtml.

Bowens, A. (ed.) 2009 Underwater Archaeology: The NAS Guide to Principles and Practices. 2nd ed. Chichester: Blackwell Publishing.

Brisbane Courier 1911 Loss of the Yongala: Marine Board Findings. The Brisbane Courier 21 June 1911.

Gleeson, M. 2000 S.S. Yongala: Townsville's Titanic. Caringbah: Max Gleeson.

MacLeod, I. and H. Steyne 2011 Managing a monitor - The case of HMVS Cerberus in Port Phillip Bay: Integration of corrosion measurements with site management strategies. Conservation and Management of Archaeological Sites 13(4):351-378.

MacLeod, I. and A. Viduka 2011 The effects of storms and diving activities on the corrosion rate of the SS Yongala (1911) site in the Great Barrier Reef. Australian Institute for the Conservation of Cultural Material Bulletin 32:134-143.

Malcolm, H.A., A.J. Cheal and A.A. Thompson 1999 Fishes of the Yongala Historic Shipwreck. CRC Reef Research Centre Technical Report 26. Townsville: CRC Reef. Retrieved 11 November 2011 from http://www.reef.crc.org.au/ publications/techreport/TechRep26.html.
Marine Board of Queensland 1911 Loss of the S.S. "Yongala". Brisbane: Anthony James Cumming, Government Printer.

McCarthy, M. 2000 Iron Steamship Archaeology: Success and Failure of the SS Xantho. New York: Plenum Publishers.

Moran, V. 2001 SS Yongala (1903-1911): A Conservation and Management Plan. Unpublished report to Museum of Tropical Queensland, Townsville.

Quinn, R. 2006 The role of scour in shipwreck site formation processes and the preservation of wreck-associated scour signatures in the sedimentary record - Evidence from seabed and sub-surface data. Journal of Archaeological Science 33:1419-1432.

Stieglitz, T.C. 2013 Habitat engineering by decadal-scale bioturbation around shipwrecks on the Great Barrier Reef mid-shelf. Marine Ecology Progress Series 477:29-40.

Townsville Maritime Museum 2008 SS Yongala. Retrieved 2 February 2011 from http://www.townsvillemaritimemuseum .org.au/the_yongala/ss_yongala.php.

Viduka, A. 2006 Managing threats to underwater heritage sites: the Yongala as a case study. In R. Grenier, D. Nutley and I. Cochran (eds), Underwater Heritage at Risk, pp.61-63. Paris: ICOMOS.

Viduka, A. 2007 SS Yongala Corrosion Survey and Condition Assessment. Unpublished report by the Museum of Tropical Queensland to Commonwealth Historic Shipwreck Program.

Waterson, P. 2012 The Impact of Severe Tropical Cyclone Yasi on the Wreck of the SS Yongala. Unpublished report to Heritage Branch, Queensland Department of Environment and Resource Management. 
Appendix A. Sections across the SS Yongala hull in 10m intervals. Section locations are shown in Figure 5.
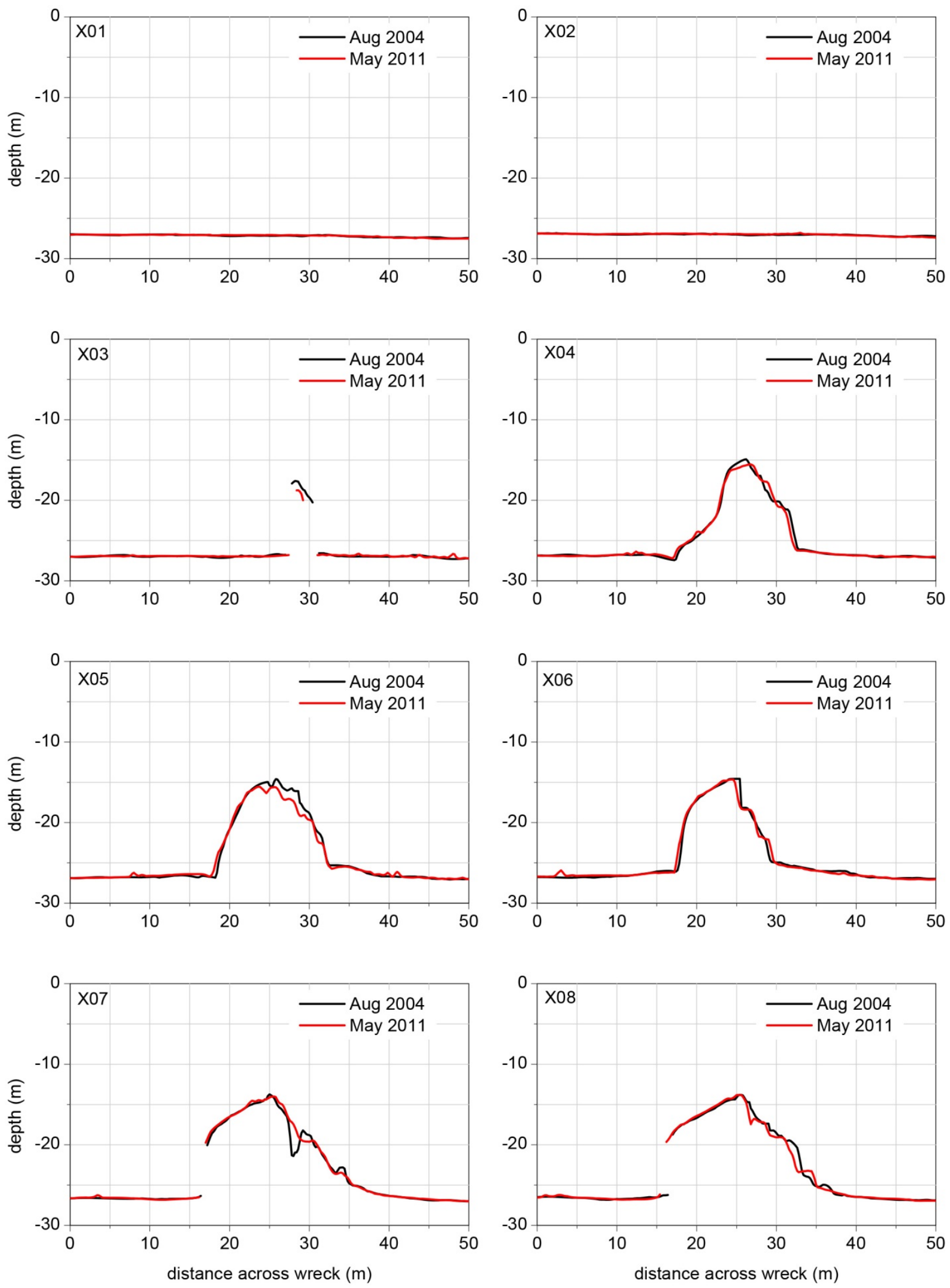

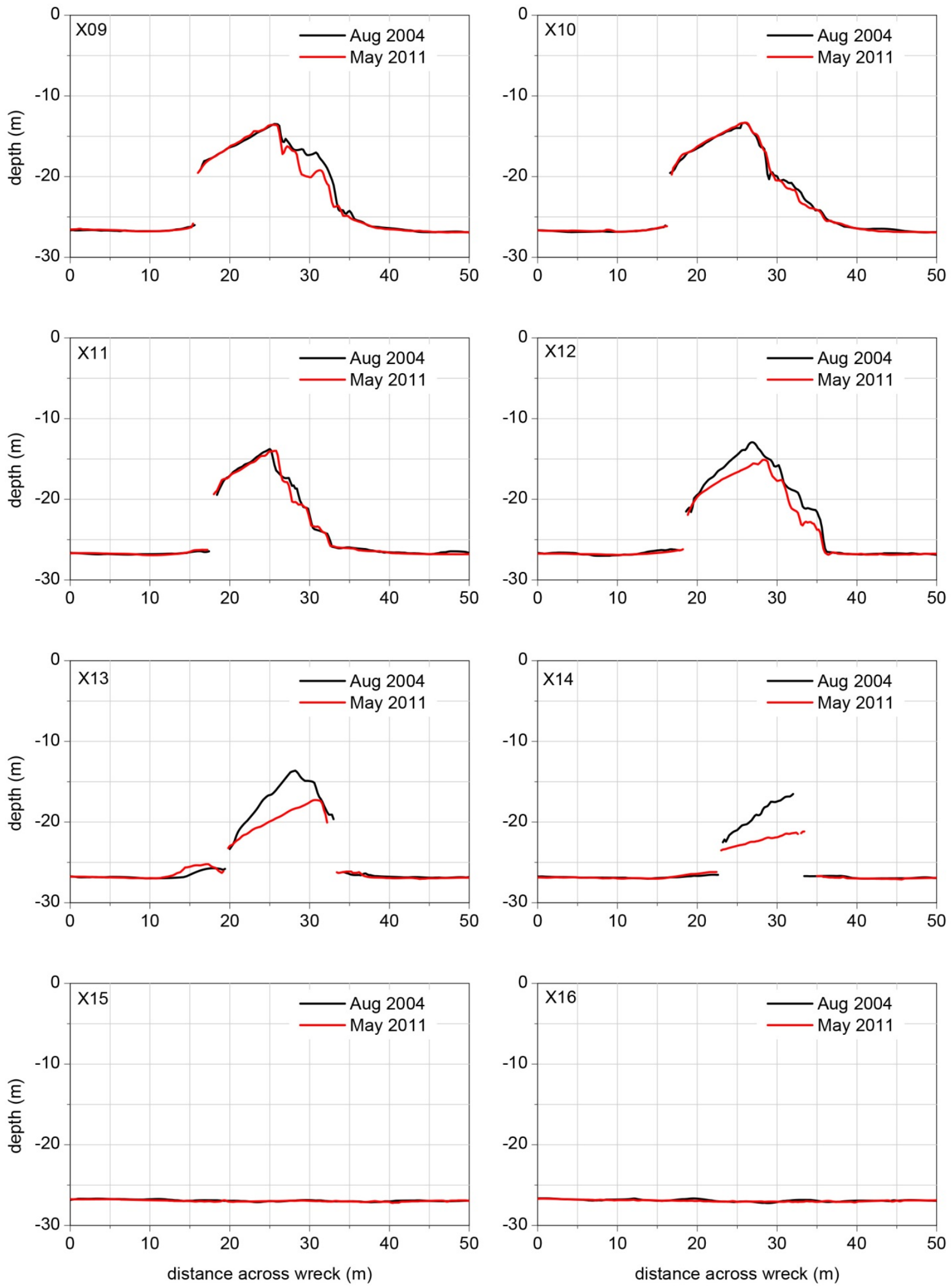
